\title{
Citra Kawasan Konservasi Penyu Pesisir Pantai Yogyakarta Menggunakan Foto Udara Berbasis EmguCV
}

\author{
Son Ali Akbar, Anton Yudhana, Arief Setyo Nugroho \\ Program Studi Teknik Elektro, Universitas Ahmad Dahlan \\ Kampus IV, Jalan Ring Road Selatan, Banguntapan, Yogyakarta 55166 \\ e-mail: sonali@ee.uad.ac.id, eyudhana@ee.uad.ac.id, arief.dulep02@gmail.com
}

\begin{abstract}
The turtle conservation area still needs to be preserved and documented through mapping the turtle landing points on the coast. Currently, efforts to map conservation areas are still carried out by direct observation and marking using simple equipment. On the other hand, the documentation process for turtle landing points is an obstacle because it is not assisted by adequate equipment. So through this research, with the implementation of unnamed aircraft vehicle (UAV) so that it can assist direct observation of the concert area through aerial photography. As for the application of the image of the conservation area, a panoramic image is made to document the conservation area map. This study builds an application for making panoramic images using the EmguCV library with Image Stitching method. The analysis of the success of the image sewing method into a panoramic image obtained an average accuracy of 94.91\%.
\end{abstract}

Keywords: Turtles; UAV; Image stitching; EmguCV

\begin{abstract}
Abstrak
Wilayah konservasi penyu masih perlu dilestarikan dan terdokumentasikan melalui pemetaan titik pendaratan penyu dipesisir pantai. Saat ini upaya kegiatan pemetaan kawasan konservasi masih dilakukan dengan cara pengamatan lansung dan penandaan menggunakan peralatan sederhana. Di sisi lain proses dokumentasi titik pendaratan penyu menjadi kendala sebab tidak dibantu dengan peralatan memadai. Maka melalui penelitian ini, dengan penerapan teknologi pesawat tanpa awak (UAV) sehingga dapat membantu pengamatan secara langsung kawasan konseravasi melalui foto udara. Adapun dengan aplikasi hasil citra area konservasi dilakukan proses pembuatan citra panorama untuk mendokumentasikan peta kawasan konservasi. Penelitian ini membangun sebuah aplikasi pembuatan citra panorama memanfaatkan library EmguCV dengan metode penjahitan citra (Image Stitching). Analisis keberhasilan metode penjahitan citra menjadi citra panorama diperoleh rerata akurasi $94,91 \%$.
\end{abstract}

Kata Kunci: Penyu; Pesawat tanpa awak; Penjahitan citra; EmguCV

\section{Pendahuluan}

Penyu merupakan salah satu binatang laut yang dilindungi di Indonesia. Bahkan di kawasan ASEAN penyu sudah menjadi hewan yang sangat dilindungi [1].Proses konservasi penyu sangat penting dilakukan untuk menyelamatkan populasi penyu dari kepunahan [2]. Saat ini telah banyak dibuat tempat untuk konservasi penyu terutama pada daerah pesisir pantai di Yogyakarta. Saat ini identifikasi atau pemantauan pertumbuhan penyu pada area konservasi masih dilakukan dengan cara mengamati lokasi pendaratan penyu di tepi pantai secara langsung.

Melihat pentingnya proses konservasi penyu perlu dilakukan kontribusi lain untuk mempermudah proses pengamatan pendaratan penyu. Dengan kemajuan teknologi terbarukan yang dapat diterapkan di berbagai bidang. Salah satunya dari penerapan teknologi pesawat tanpa awak (Unnamed Aerial Vehicle - UAV) yang belakangan ini banyak digunakan untuk berbagai bidang penelitian yang dapat menunjang potensi dalam berbagai aspek [3][4][5][6].

Maka penelitian ini akan memanfaatkan teknologi pesawat tanpa awak untuk dapat digunakan sebagai alat bantu mengumpulkan data berupa citra udara yang hasilnya akan menjadi data primer untuk dilakukan pemrosesan citra panorama kawasan pesisir pantai Yogyakarta. Hal ini bertujuan untuk membuat peta citra digital kawasan pesisir pantai yang menjadi obyek kawasan konservasi penyu. Penelitian ini akan membangun aplikasi GUI yang dapat memproses citra dari 
foto udara menjadi citra panorama digital. Metode yang diterapkan dengan memanfaatkan algoritma penjahitan citra yang tersedia pada library EmguCV.

\section{Metode Penelitian}

\subsection{Data Citra}

Pesawat UAV yang digunakan dalam penilitian ini adalah quadcopter DJI Mavic Air. Pesawat ini memiliki spesifikasi kamera 12 MP dengan resolusi video 4K Ultra HD (3480x2160) dan menghasilkan format video MP4/MOV. Pengambilan citra dilakukan dengan menentukan batas tepi pantai yang menjadi kawasan konservasi penyu di pantai Goa Cemara. Pesawat diterbangkan secara horizontal mengikuti garis pantai dengan ketinggian $\pm 30 \mathrm{~m}$. Di saat yang bersamaan proses pengambilan citra dilakukan dengan melakukan perekaman video. Pada Gambar 1 ditunjukkan batas tepi pantai dengan presentase 15\% bagian air, 85\% bagian berpasir.

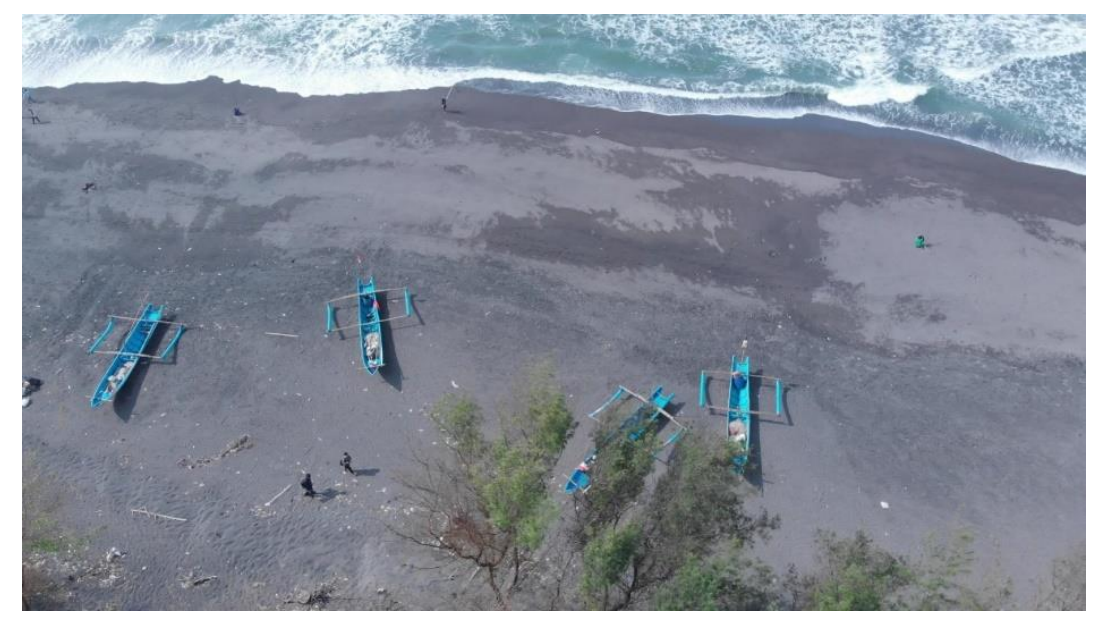

Gambar 1. Sampel citra pantai konservasi dari foto udara

\subsection{Pemisahan Data Citra}

Pada penelitian ini, pemilihan citra diambil dari sebuah video dan dilakukan Split Video menggunakan sebuah perangkat lunak Free Video to JPG Converter. Proses konversi dari video ke jpg menggunakan masukan waktu setiap selang waktu interval 5 detik. sehingga dari durasi panjang video akan menjadi beberapa frame citra.

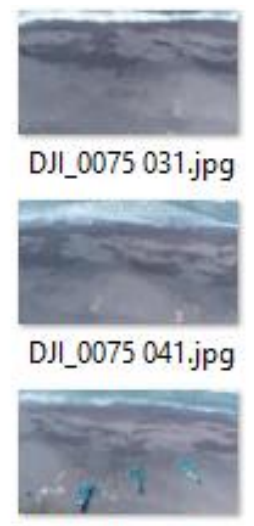

DJI_0075 051.jpg
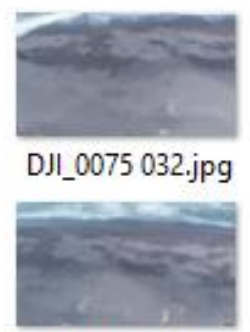

DJ_0075 042.jpg

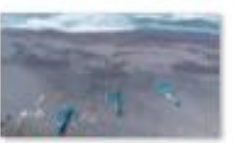

DJ_0075 052.jpg

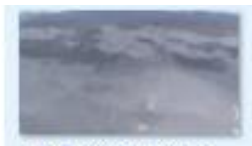

DII_0075 033.jpg

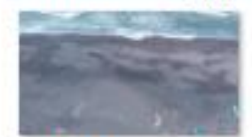

DII_0075 043.jpg

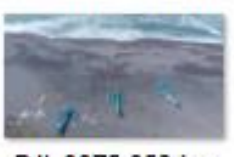

DJ_0075 053.jpg

Gambar 2. Hasil seleksi citra

Citra hasil setelah dilakukan proses Split selanjutnya diseleksi untuk menentukan citra yang akan dijahit sesuai dengan kemiripan pada sebagian citra yang lain. Pada Gambar 2 menunjukan hasil split citra yang sudah diseleksi. 


\subsection{Panorama Citra}

Pada penelitian ini metode Stitcher dari Library EmguCV digunakan dalam proses penjahitan citra [7]. Metode ini telah tersedia dalam EmguCV sehingga hanya diperlukan pemanggilan dalam penggunaannya [8]. Proses penjahitan citra diperlukan sebuah algoritma untuk menentukan model matematika yang sesuai dengan koordinat piksel dalam satu gambar. Untuk deteksi fitur diperlukan nilai korespondensi antar citra. SIFT dan SURF merupakan algoritma yang sering digunakan untuk menetukan nilai Keypoint atau nilai titik sudut pada citra [9] [10].

Setelah nilai titik poin didapatkan citra akan saling bertindih atau terjadi proses penjahitan antara beberapa citra. Transformasi proyektif dapat digunakan untuk mencocokkan dalam penjahitan citra yang secara matematis dapat ditulis sebagai berikut,

$$
x^{\prime}=H \cdot x,
$$

Nilai $x$ merupakan nilai koordinat lama, $x^{\prime}$ adalah nilai titik yang citra yang diubah, sedangkan $\mathrm{H}$ merupakan nilai matriks homografi. Perhitungan matrik homografi [11] dapat dilihat pada persamaan berikut,

$$
H a b=R-\frac{t n^{T}}{d},
$$

Dengan $R$ merupakan matrik rotasi dari salah satu bagian yang diputar. Notasi $t$ adalah vektor dari kedua bagian. Notasi $n$ dan $d$ merupakan vektor normal dan jarak masing masing. Pada penelitian ini perangkat akan menghitung secara otomatis nilai matriks untuk melakukan proses penjahitan menggunakan Library EmguCV yang telah tersedia.

\subsection{Perancangan Desain Antarmuka}

Antarmuka perangkat lunak yang digunakan pada penelitian ini menggunakan Visual Studio 2017 dengan bahasa pemrograman C\# dan Library EmguCV untuk proses pengolahan citra [12]. Metode yang digunakan adalah memasukkan dan penjahitan citra hasil seleksi untuk dijadikan sebuah panorama dengan metode Stitching. Pada Gambar 3 menunjukan bentuk rancangan dari antarmuka perangkat lunak.

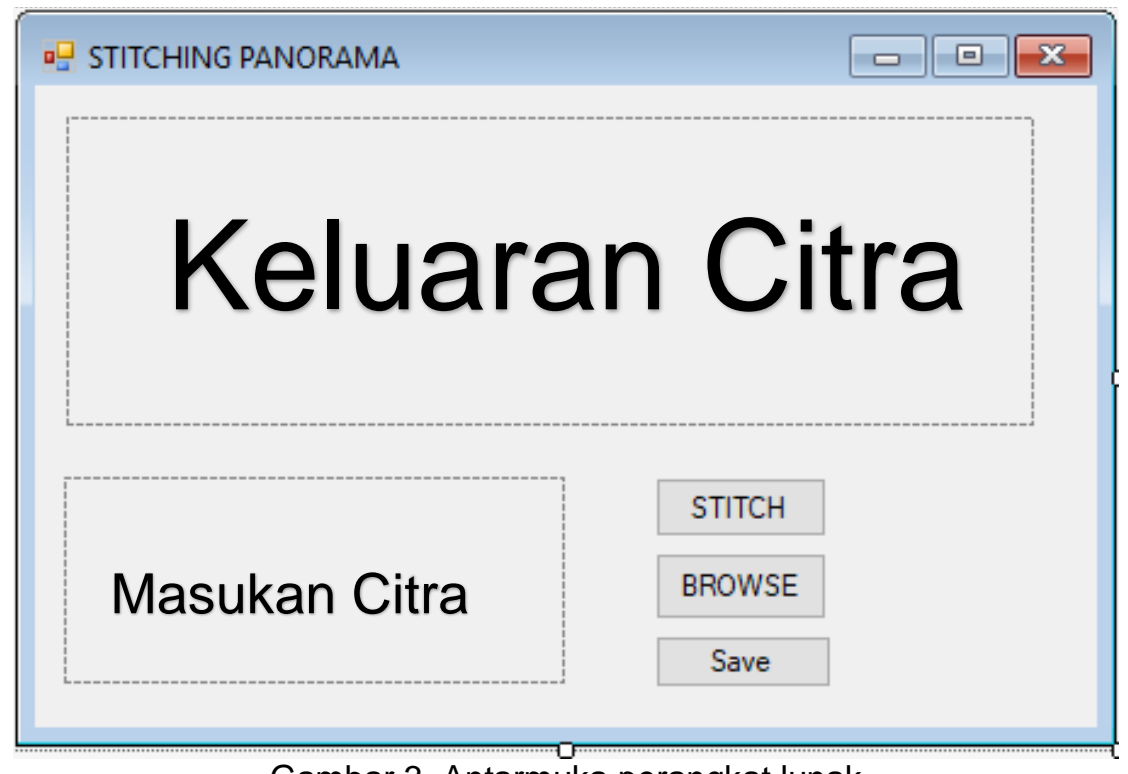

Gambar 3. Antarmuka perangkat lunak

Pada tombol Browse antarmuka akan mengarahkan pengguna pada file dokumen dari perangkat yang digunakan untuk memilih citra yang akan digabungkan. Pada pilihan ini digunakan fungsi filter untuk memilih citra yang hanya berekstensi .jpg, .png, .gif. Tombol Stitch digunakan untuk mulai penjahitan citra setelah dimasukkan. Sedangkan tombol Save digunakan untuk menyimpan hasil citra penjahitan ke dalam folder penyimpanan 


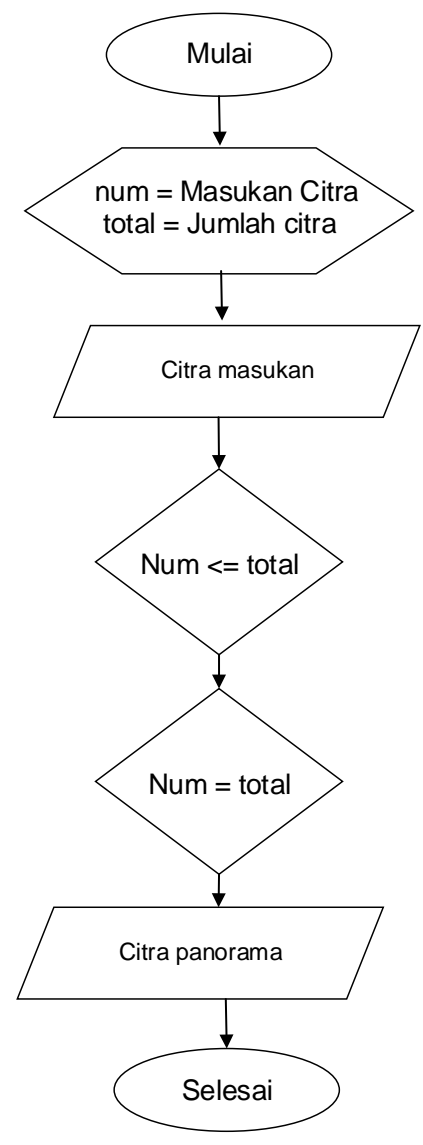

Gambar 4. Pemrosesan citra dengan GUI

Berdasarkan diagram alir pada Gambar 4, pertama akan ditentukan jumlah citra yang akan dimasukkan. Program akan menghitung citra masukkan secara otomatis sampai jumlah total terpenuhi saat citra dimasukkan dan program akan melakukan penjahitan secara otomatis.

Sedangkan proses penggunaan perangkat lunak, Citra yang telah terseleksi akan dimasukkan menggunakan tombol Browse. Citra hasil masukkan akan ditampilkan kedalam sebuah PictureBox1 (Masukkan Citra). Setelah citra yang dipilih ditampilkan pada PictureBox1 selanjutnya pengguna akan memilih tombol Stitch untuk mulai menggabungkan citra. Proses akan terus diulangi sampai citra yang dimasukkan sesuai dengan jumlah citra yang diinginkan. Setelah seluruh citra digabungkan maka perangkat lunak akan secara otomatis menampilkan hasil Stitching yang akan ditampilkan pada PictureBox2 (Keluaran Citra). Untuk menyimpan hasil Penjahitan maka dapat digunakan tombol Save yang akan menyimpan pada perangkat.

\section{Hasil dan Pembahasan}

Data foto udara melalui pesawat tanpa awak yang diperoleh dari kawasan konservasi penyu di daerah pesisir pantai Yogyakarta dilakukan proses pemisahan citra dari rekaman video. Proses pemisahan citra didapat sebanyak 105 citra dari rekaman video. Selanjutnya dilakukan proses seleksi citra dengan cara mengurangi kesamaan (similarity) citra yang digunakan. Maka diperoleh 19 citra yang mewakili data primer untuk dilakukan pemrosesan penjahitan citra. Dari 19 citra yang digunakan langkah berikutnya adalah melakukan proses penjahitan dengan tiga kali pemrosesan yang bertujuan mengurangi derau dan waktu pemrosesan.

\subsection{Penjahitan 6 Citra}

Pada pengujian pertama digunakan 6 buah citra untuk mengetahui tingkat keberhasilan proses penjahitan citra. Pada Gambar 5 menggunakan 6 buah citra sebagai citra masukan pemrosesan citra panorama yang hasilnya ditunjukkan pada Gambar 6. 

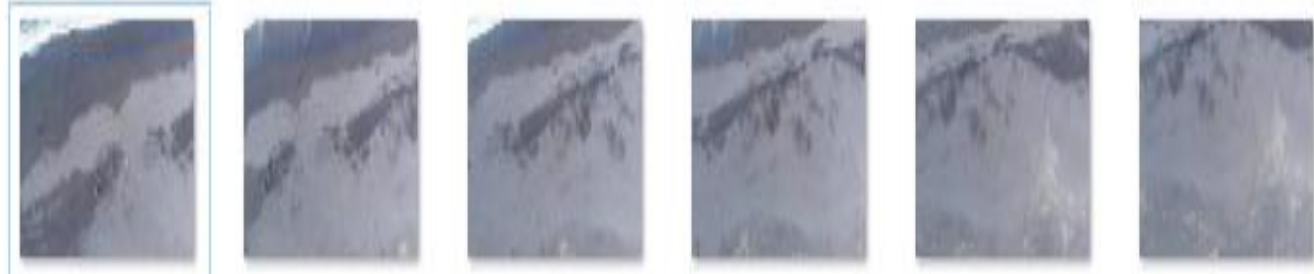

Gambar 5. Citra masukan terdiri dari 6 citra

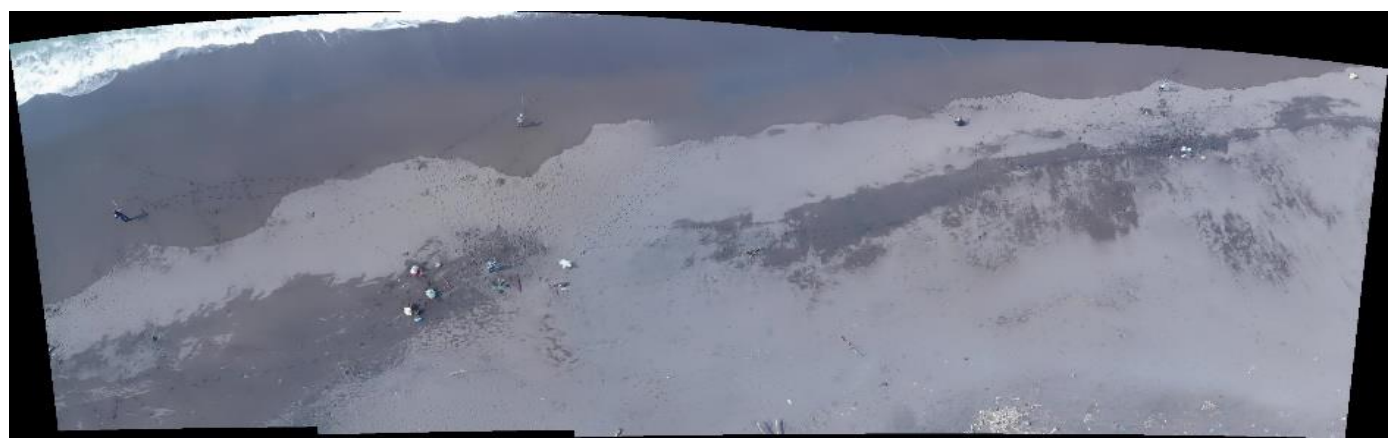

Gambar 6. Hasil panorama 6 buah citra

\subsection{Penjahitan 10 Citra}

Pada pengujian kedua digunakan 10 buah citra dengan menggabungkan 6 citra yang pertama dengan 4 citra baru untuk mengetahui tingkat keberhasilan proses penjahitan citra. Pada Gambar 7 menunjukkan 10 buah Citra yang akan dijahit. Gambar 8 merupakan hasil penjahitan 10 citra.
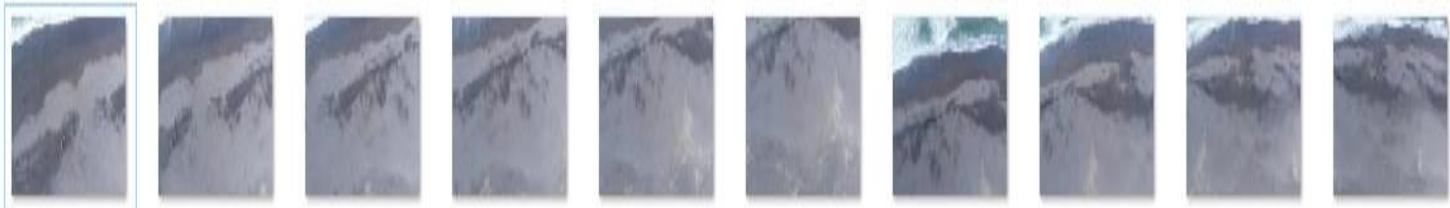

Gambar 7. Citra masukan terdiri dari 10 citra

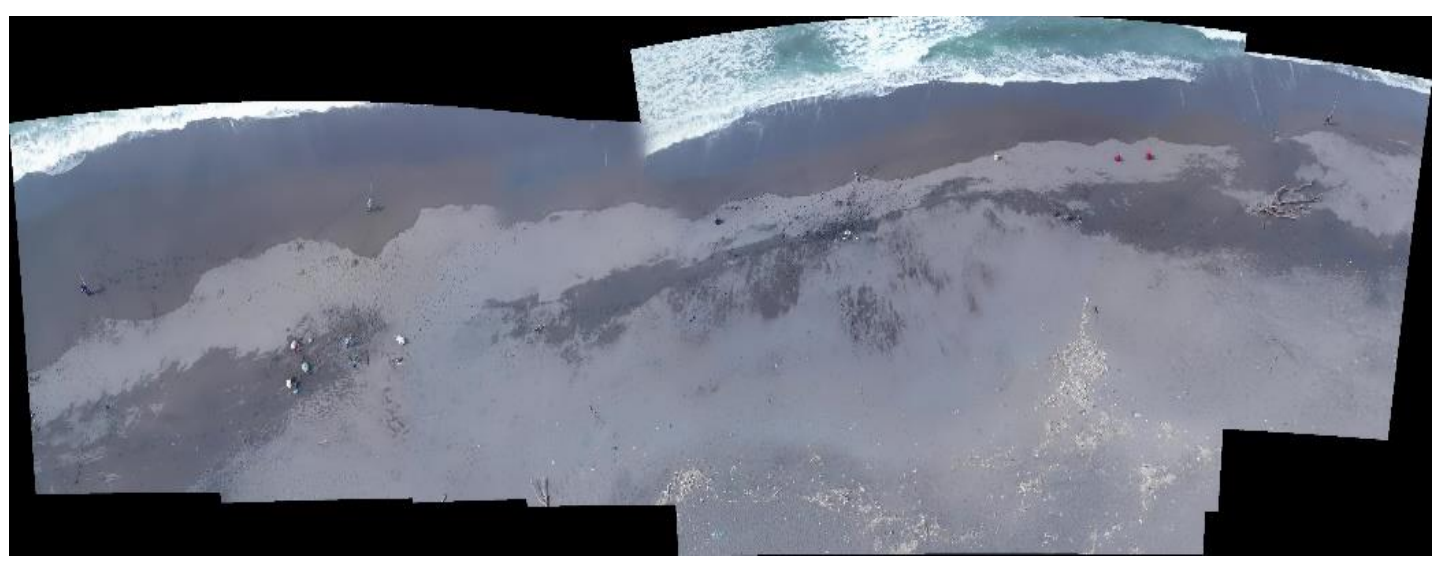

Gambar 8. Hasil panorama 10 buah Citra

\subsection{Penjahitan 19 Citra}

Pada Gambar 10 merupakan hasil dari seluruh penjahitan citra dengan menambahkan 9 citra pada penjahitan sebelumnya. Pada Gambar 9 menunjukkan 19 Citra masukkan 

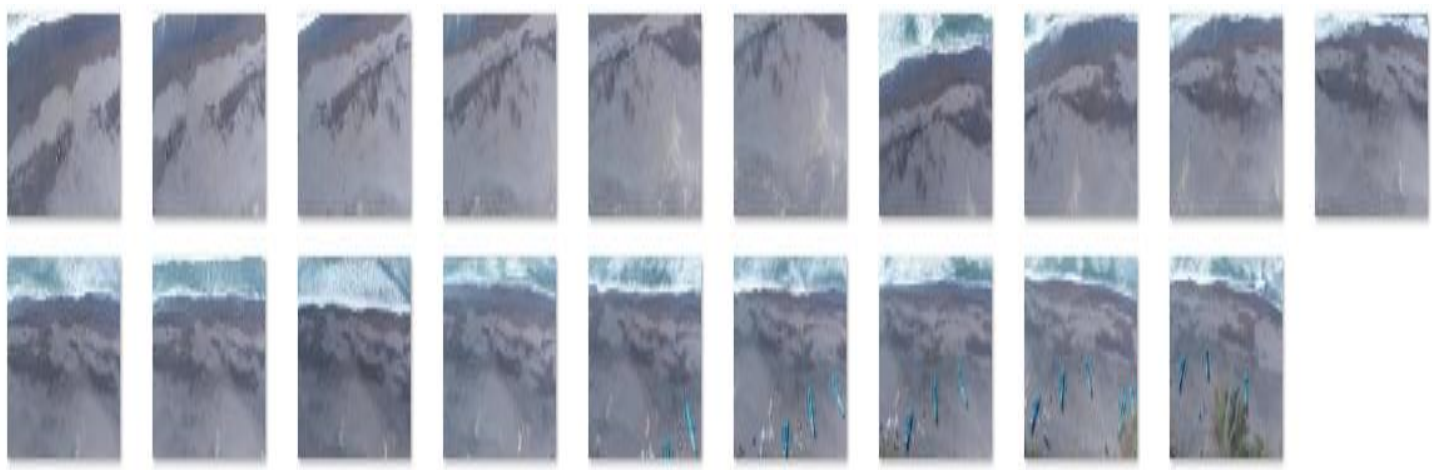

Gambar 9. Citra masukan terdiri dari 19 citra

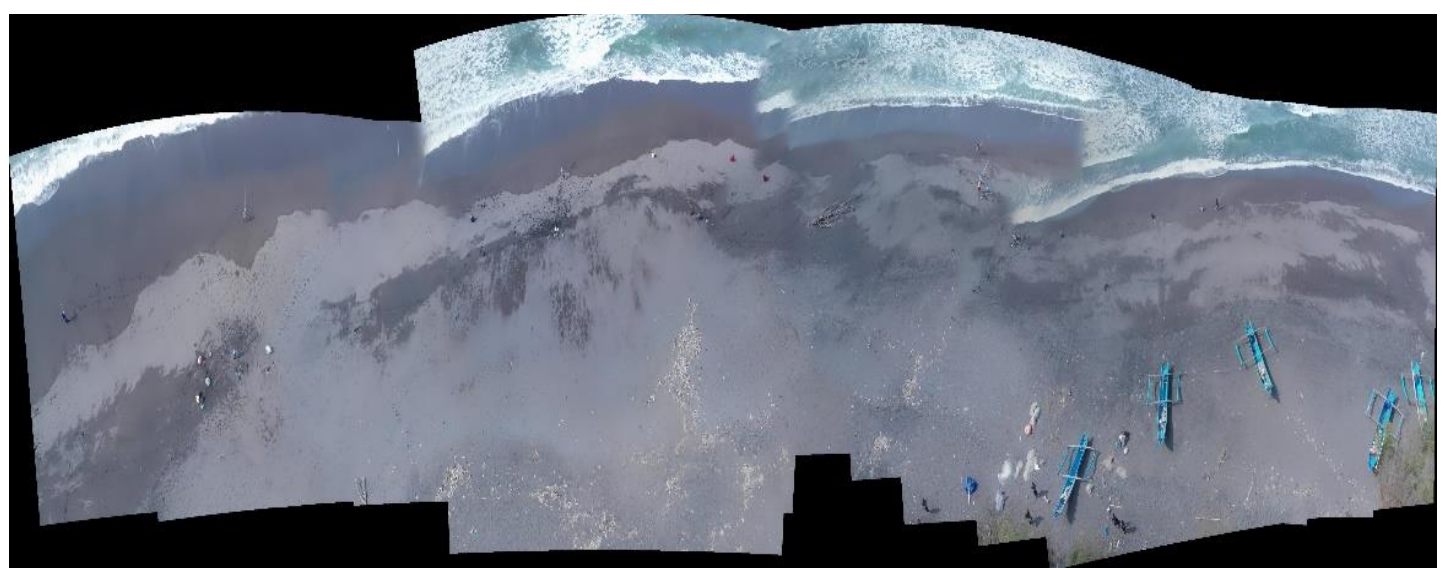

Gambar 10. Hasil panorama 19 buah Citra

Tabel 1. Hasil performa penjahitan citra

\begin{tabular}{ccc}
\hline Masukan Citra & Akurasi (\%) & Kesalahan (\%) \\
\hline 6 Citra & 100 & 0 \\
\hline 10 Citra & 90 & 11,11 \\
\hline 19 Citra & 94,73 & 5,56 \\
\hline Rerata & 94,91 & 5,57 \\
\hline
\end{tabular}

\section{Kesimpulan}

Hasil penelitian ini berupa citra panorama kawasan konservasi pendaratan penyu yang lebih nyata berbanding dengan menggunakan data citra satelit. Penelitian ini juga membangun GUI untuk memudahkan dalam operator melakukan proses penjahitan citra panorama tersebut sehingga hasilnya dapat langsung menjadi referensi bagi kalangan penelitian dan bermanfaat untuk tujuan penetapan kawasan konservasi. Penelitian ini berhasil memanfaatkan algoritma penjahitan citra dari perpustakaan EmguCV. Hal ditunjukkan dengan kualitas peforma pemrosan citra mencapai akurasi $94,91 \%$. Penelitian selanjutnya untuk mengoptimalisasi kualitas pemrosesan maka akan dilakukan penerapan uji beberapa metode dan alogritma penjahitan citra seperti SURF, SIFT dan RANSAC yang dapat juga diaplikasikan pada sistem GUI.

\section{Referensi}

[1] Sunardi, A. N. Noor Zirwatul, M. Azrul, and A. Yudhana, "Prevent turtle trap in the fishing gear using ultrasound," Proc. 2013 IEEE 8th Conf. Ind. Electron. Appl. ICIEA 2013, no. 2001, pp. 1382-1387, 2013.

[2] T. Beugeling and A. Branzan-Albu, "Computer vision-based identification of individual turtles using characteristic patterns of their plastrons," Proc. - Conf. Comput. Robot Vision, CRV 2014, pp. 203-210, 2014.

[3] Y. IMAMURA, S. OKAMOTO, and J. H. LEE, "807 Human Tracking by a Multi-rotor Drone Using HOG Features and Linear SVM," Proc. Conf. Chugoku-Shikoku Branch, vol. 2016.54, no. 0, p._807-1_-_807-3_, 2016.

Citra Kawasan Konservasi Penyu Pesisir Pantai Yogyakarta Menggunakan Foto Udara Berbasis 
[4] S. Sankarasrinivasan, E. Balasubramanian, K. Karthik, U. Chandrasekar, and R. Gupta, "Health Monitoring of Civil Structures with Integrated UAV and Image Processing System," Procedia Comput. Sci., vol. 54, pp. 508-515, 2015.

[5] F. C. Pereira and C. E. Pereira, "Embedded image processing systems for automatic recognition of cracks using UAVs," IFAC-PapersOnLine, vol. 28, no. 10, pp. 16-21, 2015.

[6] K. N. Tahar and A. Ahmad, "An Evaluation on Fixed Wing and Multi-Rotor UAV Images using Photogrammetric Image Processing," World Acad. Sci. Eng. Technol., vol. 7, no. 1, pp. 391396, 2013.

[7] D. Von Söhsten and S. Murilo, "Multiple face recognition in real-time using cloud computing, Emgu CV and Windows Azure," Int. Conf. Intell. Syst. Des. Appl. ISDA, pp. 137-140, 2014.

[8] F. Abubakar, "Implementation of Speed Up Robust Feature for Detection and Tracking of Inanimate Objects," Int. J. Comput. Sci. Mob. Comput., vol. 3, no. 1, pp. 325-333, 2014.

[9] E. Rublee, V. Rabaud, K. Konolige, and G. Bradski, "ORB: An efficient alternative to SIFT or SURF," Proc. IEEE Int. Conf. Comput. Vis., no. May, pp. 2564-2571, 2011.

[10] Z. Hamizan and R. Sumiharto, "Sistem Pentautan Citra Udara Menggunakan Algoritme SURF dan Metode Reduksi Data," IJEIS (Indonesian J. Electron. Instrum. Syst., vol. 7, no. 2, p. 127, 2017.

[11] E. Özüa and S. Ertürk, "Homography Matrix Decomposition Based Video Synchronization Approach," in 22nd Signal Processing and Communications Application Conference, 2014, pp. 2043-2046.

[12] J. Shieh, Y. Liao, G. Lioao, and Y. Liou, "Dynamic Image Stitching for Panoramic Video". Int. Journal of Eng. and Techno. Inovation. vol.4, no.4, pp. 260-268, 2014. 